\title{
Optical Switching for Dynamic Distribution of Wireless-Over-Fiber Signals in Active Optical Networks
}

Vegas OImos, Juan José; Rodes, Guillermo; Tafur Monroy, Idelfonso

Published in:

Journal of Optical Communications and Networking

Link to article, DOI:

$10.1364 / J O C N .4 .000622$

Publication date:

2012

Link back to DTU Orbit

Citation (APA):

Vegas Olmos, J. J., Rodes, G., \& Tafur Monroy, I. (2012). Optical Switching for Dynamic Distribution of

Wireless-Over-Fiber Signals in Active Optical Networks. Journal of Optical Communications and Networking, $4(8), 622-627$. https://doi.org/10.1364/JOCN.4.000622

\section{General rights}

Copyright and moral rights for the publications made accessible in the public portal are retained by the authors and/or other copyright owners and it is a condition of accessing publications that users recognise and abide by the legal requirements associated with these rights.

- Users may download and print one copy of any publication from the public portal for the purpose of private study or research.

- You may not further distribute the material or use it for any profit-making activity or commercial gain

- You may freely distribute the URL identifying the publication in the public portal 


\title{
Optical Switching for Dynamic Distribution of Wireless-over-Fiber Signals in Active Optical Networks
}

\author{
J.J. Vegas Olmos, G. Rodes, and I. Tafur Monroy
}

\begin{abstract}
In this paper, we report on an experimental validation of dynamic distribution of wireless-over-fiber by employing optical switching using semiconductor optical amplifiers; we also provide a channel distribution scheme and a generic topology for such optical switch. The experiment consists of a four wavelength division multiplexed (WDM) channel system operating on a WiMax frequency band, and employing an orthogonal frequency-division multiplexing (OFDM) modulation at $625 \mathrm{Mbit} / \mathrm{s}$ per channel, transmission of the data over $20 \mathrm{~km}$ of optical fiber, and active switching in a one-by-sixteen active optical switch. The results show a negligible power penalty on each channel, for both the best and the worst case in terms of interchannel crosstalk. The presented system is highly scalable both in terms of ports count and throughput, a desirable feature in highly branched access networks, and is modulation and frequency band independent.
\end{abstract}

Index Terms - optical access network, active optical network, radio-over-fiber, WiMax, wirelessover-fiber, semiconductor optical amplifier, optical switch.

\section{INTRODUCTION}

$\mathbf{T}$ he ever growing demand of bandwidth by end users has put a lot of pressure on access networks, triggering the adoption of fiber systems in access almost two decades ago [1]. Depending on the requirements and features of the end users in terms of latency, quality of service (QoS) or service layer agreements (SLA), optical access networks have evolved in different directions [2]: high capacity at low price is supported by passive optical networks (PON) while quality assurance and security are supported by active optical networks (AON) [3].

Vendors and operators are now turning their eye to new markets where optics can be used effectively. Mobile

Manuscript received XXX X, 2012.

J.J. Vegas Olmos, G. Rodes, and I. Tafur Monroy are with DTU Fotonik, Technical University of Denmark, Ørsted Plads 358, Kgs. Lyngby, 2800, Denmark. (e-mail: jjvo@fotonik.dtu.dk). backhaul is a target market [4], since mobile traffic is growing exponentially - new gadgets along with killer applications are fueling such growth. Baseband technologies can support mobile backhaul effectively at current rates. However, due to the location of new licensefree available frequency bands and the development of radio-over-fiber (RoF) technologies - allowing generation, distribution and reception of micro- and millimeter wave band signals optically, migration towards wireless-overfiber scenarios are likely [5][6]. Traditional constraints of RoF systems such as highly linear requirements for the modulator and chromatic-dispersion induced power fading during transmission are by now manageable. In any case, there is a general consensus about the exponential growth of mobile data traffic: CISCO's white paper on traffic forecast predicts a 26 -fold increase of global mobile data traffic between 2010 and 2015 and a 10-fold increase in the average mobile network connection speed [7].

We hence need to provide solutions capable of effectively handling wireless-over-fiber signals regardless their nature in terms of frequency operation, modulation format, bitrate and so on. Furthermore, the system must be able to scale graciously in terms of channels and capacity, allowing for future upgrades in terms of wireless technologies. These requirements set a new range of challenges in the field of RoF, such as multi-channel operation, extended reach, extreme performance limits (including linearity, especially in optical components), cost issues related to the deployment of millimeter wave equipment in the field and architectural limitations [8]. Current state-of-the-art research on RoF have shown that high-capacity radio signals can be generated, transmitted and successfully recovered at high frequency bands, such at $60 \mathrm{GHz}$ and 75 $110 \mathrm{GHz}$ band [9], even over long distances [10].

However, these demonstrations are limited to static distribution of RoF signals, and neglect the dynamism required in mobile-supporting networks, which is achieved through switching. Previous demonstrations of RoF switching included a WiMAX-over-fiber demonstration for a high speed train system [11], but the scalability was limited and the throughput less than few Mbit/s, and a passive distribution of twelve WiMax signals operating at $2.6 \mathrm{GHz}$ [12]. Technologies demonstrating optical switches for RoF have also been presented, such a 3D microelectromechanical system (MEMS) for in-building networks [13], a SOA-based switch with reduced scalability 
[14] and wavelength packet switch based on distributed Bragg reflectors [15].

In this paper, we propose to employ a one-by-sixteen active switch based on semiconductor optical amplifiers (SOAs) and arrayed-waveguides (AWGs) to provide fast switching for wireless-over-fiber systems, enabling novel unicast and multicast distribution. The employed optical switch, originally designed for high capacity interconnects, enables quick reconfiguration and selective-delivery, hence going one step beyond up-to-date reports on optical switching for RoF signals. Furthermore, the optical switch is modulation format independent, permitting to use it with different wireless technologies at different frequency bands. Specifically, we demonstrated four WDM channel switching after transmission through $20 \mathrm{~km}$ of standard single mode fiber (SSMF), which equals the length of a traditional PON. The RoF signals emulated WiMax signals by being set to operate at the $5 \mathrm{GHz}$ frequency band, employing orthogonal frequency-division multiplexing (OFDM) and operating at $625 \mathrm{Mbit} / \mathrm{s}$.

The paper is organized as follows: Section II introduces the system architecture, technologies for switching and the optical switch employed in this research. Section III presents the experimental setup and a characterization of the switching elements. Then, quantitative results in terms of bit error rate (BER) are presented in Section IV. Finally, conclusions and further work are given in Section V.

\section{System ARChitecture AND Design Choices}

This section describes the advantages of an AON system used for wireless-over-fiber delivery employing RoF technologies, technologies for optical switching, and then introduces the optical switch employed during the experimental assessment.

\section{A. Active optical network and radio-over-fiber}

PON systems have become very popular during the last lustrum because they offer both low capital and operational expenditures, which are critical factors in access networks. In fact, less than a decade ago, PON and AON systems had a similar market share. It is now becoming obvious that PON efficiency is however low in terms of bandwidth utilization and power budget issues limit the splitting ratio and the attainable link lengths. Furthermore, the intrinsic nature of the distribution approach (point-to-multipoint multicast) may raise concerns in terms of security, especially in industrial or business environments. AON approaches are emerging back in this area to cope with such problems: data can be effectively managed at a traffic engineering level (i.e., path control, bandwidth reservation, prioritization, etc.), while ensuring secure unicast distribution and simple and flexible designs. When considering AON networks, in the context of wireless systems, the advantages are clear: we can better handle data distribution while preserving the mobile nature of the end users. Figure 1 shows a distribution system of wireless signals employing a consolidated central office (CO). A consolidated CO serves several clusters of access networks (either AON or PON networks) centralizing the management of the system and employing a single physical platform.

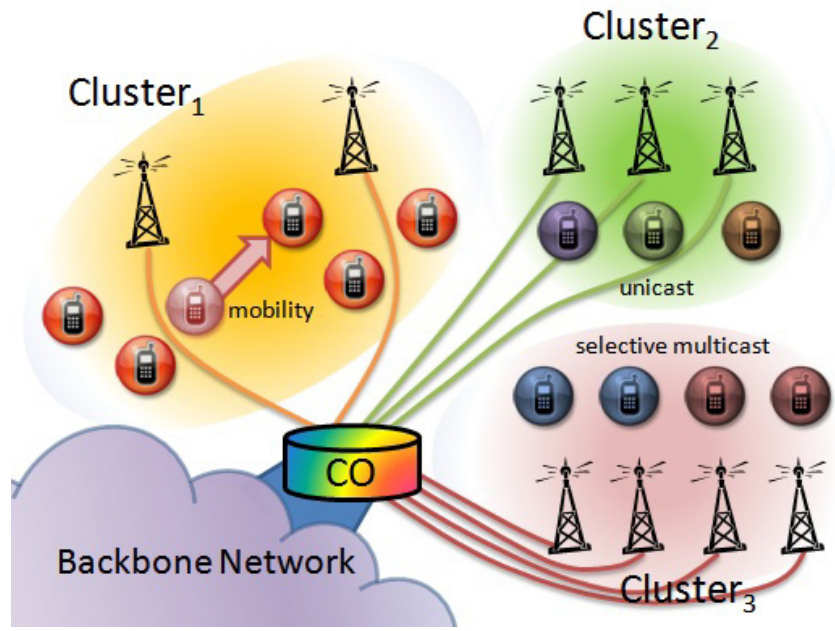

Fig. 1. General architecture of an active optical network for mobile applications, including unicast and selective multicast capabilities. CO: central office.

Furthermore, concerns on security [16] and high mobility [17] seem to indicate active solutions such AON may be in favor of system designers, provided that cost and energy consumption are maintained within reasonable limits. AON networks, in combination with RoF technologies, are hence an interesting way of enabling a higher degree of reconfigurability in scenarios in which the end user is mobile per se, and requires low-latency, high-throughput and physical layer security features.

\section{B. Optical switches - technology of choice}

All-optical switching fabrics play a central role in allowing switching in the optical domain, avoiding the need for $\mathrm{O} / \mathrm{E} / \mathrm{O}$ conversions [17]. There are a plethora of technologies used to construct complex optical switches (i.e. more than two output ports): optomechanical switches [18][19], MEMS [20], electrooptic switches based on lithium niobate $\left(\mathrm{LiNbO}_{3}\right)$ [21] or active vertical coupling [22], microring resonators [23], thermooptic switches [24], among others. Benchmarking and technical comparisons can be found analyzing the suitability of such technologies for optical switching [25][26]

All these fabrics are passive in nature, meaning that no gain occurs. Hence, there are inherent limitations in terms of scalability due to the decay of power when several individual switches are cascaded. Semiconductor optical amplifiers (SOAs) are promising alternatives as switch fabrics precisely because they can provide gain along with fast switching time [27].

\section{Optical switch based on SOAs}

The optical switch fabric employed to demonstrate active switching of RoF signals is based on a three-stage architecture, initially proposed for the optical shared memory supercomputer interconnect system (OSMOSIS) project [28][29]. The OSMOSIS interconnect is a broadcastand-select optical switch fabric using SOAs, acting as on-off gates, and AWGs as filters. Such architecture was initially 
intended for supercomputer interconnects, in which highspeed, low-latency and high-throughput are key. This optical switch can serve several clusters, each cluster being composed of several and identical wavelength channels; the clusters are orderly placed on the optical domain and processed independently. Figure 2 shows the wavelength allocation, consisting of $\mathrm{N}$ clusters, of $\mathrm{M}$ base stations (BSs) each.

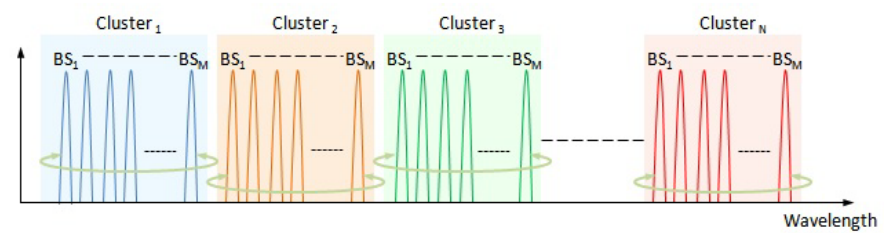

Fig. 2. Wavelength allocation. Clusters $1-N$ comprise base station channels 1-M. BS: base station.

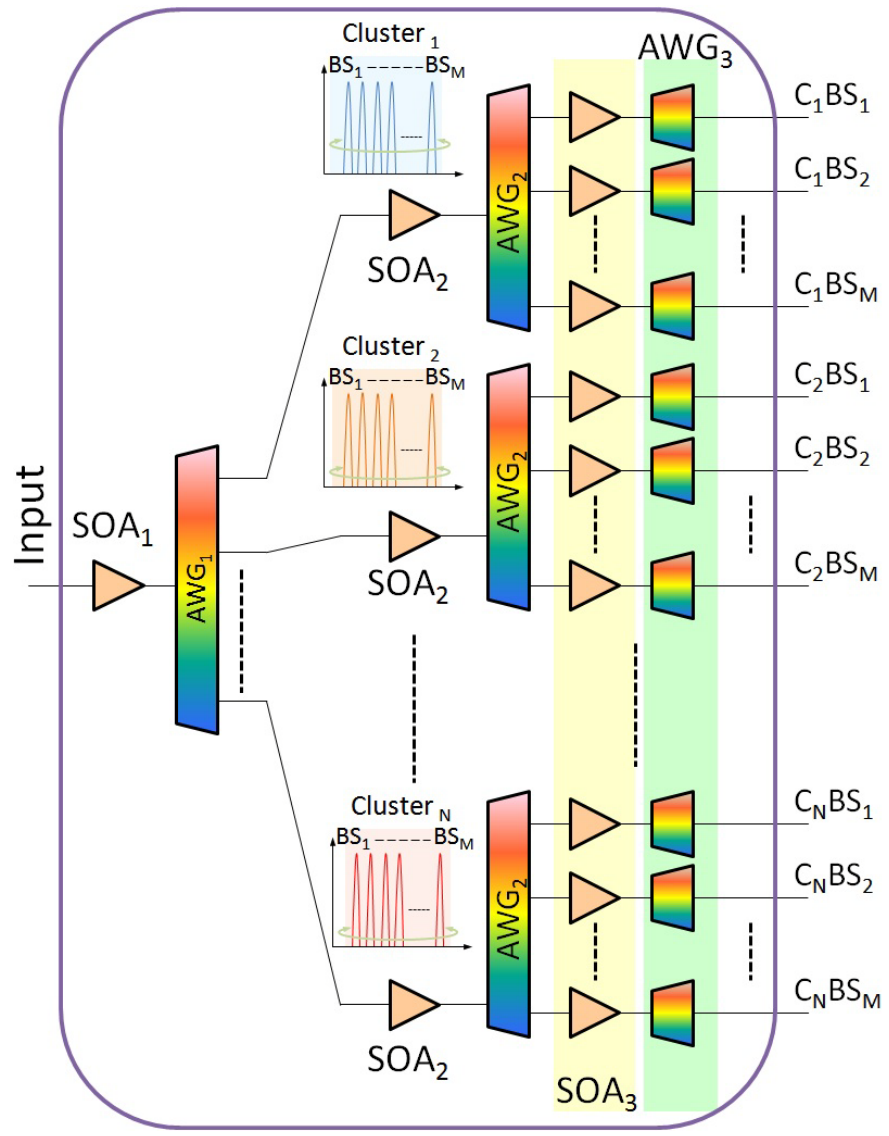

Fig. 3. Internal schematic of a generic switch. SOA: semiconductor optical amplifier, AWG: arrayed-waveguide, C: cluster, BS: base station.

Figure 3 shows the internal architecture of a generic switch fabric. The input of the optical switch conveys the spectra shown in Figure 2. SOA1 amplifies all the clusters while AWG1 separates the clusters. The second set of SOAs, namely SOA2, act as on-off gates for each cluster, which is further disassembled by the second set of AWGs, in this case AWG2. At this stage each channel has been already separated, and a final round of SOAs, SOA3, decides whether the channel must be fed into the BS through one last AWG. This last AWG acts as a filter to remove the amplified spontaneous emission (ASE) noise. In fact, the last AWG may have the same size as AWG2 with matching wavelength features or be an independent AWG. Hence, the switch allows to unicast the channel to a single BS, or selective multicast the channel to the desired BSs by making use of the last round of SOAs. In the event of activating all the amplifiers corresponding to the SOA3 round, the system emulates in fact a conventional point-tomultipoint PON system. It is worth pointing out that the architecture and further experimental demonstration provided in this paper only deals with the downstream distribution; however, once the optical switch is demonstrated by backfeeding the upstream channels into the switch [30] or duplicating the switch to collect the upstream flows [31], a bidirectional system can be implemented based on the same technological solution.

Although the experimental demonstration conducted in the next section was done with discrete components, the proposed architecture can be photonically integrated, using for example active-passive InGaAsP-InP epitaxy as in [32]. Current technologies allow combined integration of passive and active components, drastically reducing the footprint and decreasing the power consumption of the active devices while preserving their features. Specifically, SOAs can be designed to operate at the desired wavelength ranges and gain levels. Furthermore, whereas employing SOAs for baseband signals has limitations in terms of bitrate due to the natural recovery time of the gain of the SOA (typically $\sim 100 \mathrm{ps}$ ) [31], RoF signals employing OFDM modulation are less likely to experience degradation due to this effect on the SOA because OFDM signals utilize a plurality of carriers to convey the data, effectively reducing the bitrate. SOAs are also fairly transparent to phase information, enabling their usage together with advanced modulation formats.

\section{EXPERIMENTAL SETUP}

Figure 4 shows the experimental setup. To emulate the schematic depicted in Fig. 3, four lasers operating at $\lambda_{1}=1547.65 \mathrm{~nm}, \quad \lambda_{2}=1548.48 \mathrm{~nm}, \quad \lambda_{3}=1549.27 \mathrm{~nm}, \quad$ and $\lambda_{4}=1550.12 \mathrm{~nm}$, were combined and simultaneously modulated by a Mach-Zehnder Modulator (MZM) with a $5 \mathrm{GHz}$ OFDM quadrature amplitude modulation (4-QAM) signal with 128 subcarriers operating at $625 \mathrm{Mbit} / \mathrm{s}$ and a bandwidth occupancy of $312.5 \mathrm{MHz}$. The four channels were then transmitted through a $20 \mathrm{~km}$ of SSMF with approximately $6.5 \mathrm{~dB}$ of insertion losses, and then fed to the optical switch. 


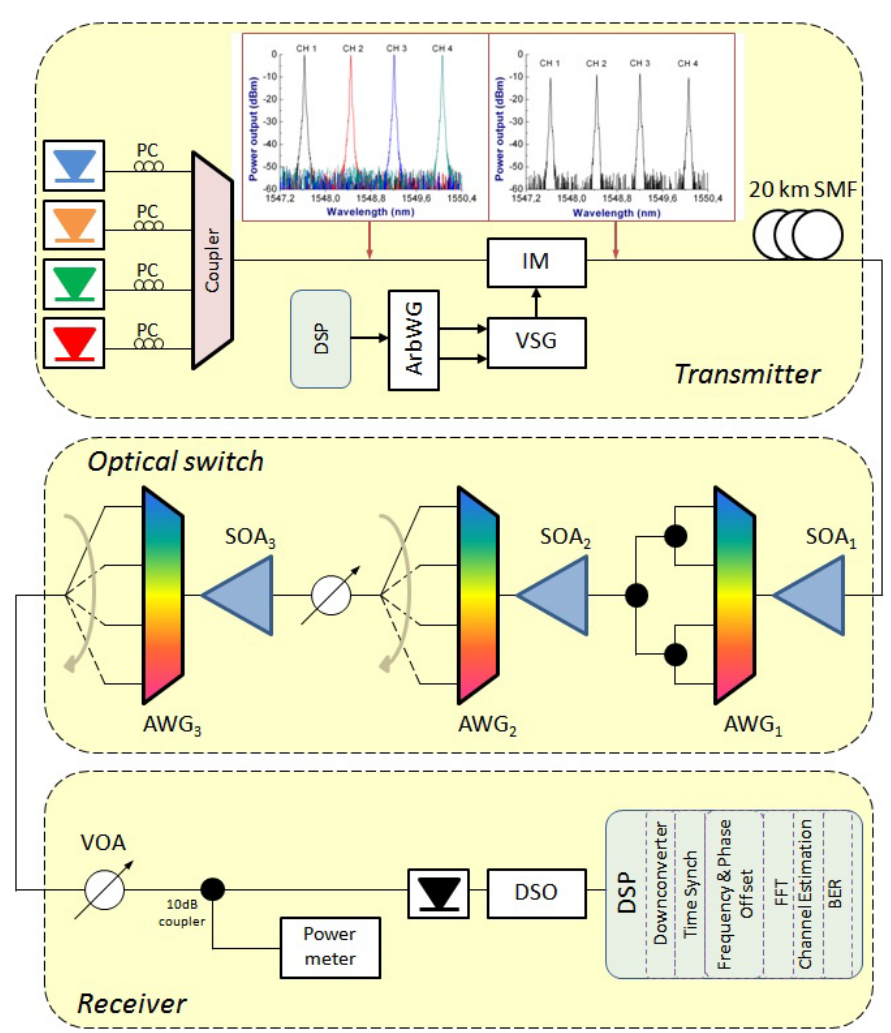

Fig. 4. Experimental setup. The insets show the optical spectra of the generated channels after being passively combined and also after modulation. PC: polarization controller, VSG: vector signal generator, ArbWG: arbitrary wave generator, DSP: digital signal processing, MOD: optical modulator, SOA: semiconductor optical amplifier, AWG: arrayed wave-guide, VOA: variable optical attenuator, DSO: data storage oscilloscope.

The SOAs employed in the experiment are characterized in Fig. ‥ As it can be observed, the SOAs operate as attenuators when the bias voltage is less than $0.6 \mathrm{~V}$, and as amplifiers when the bias is over $1.2 \mathrm{~V}$. During the experiments, $\mathrm{SOA}_{\text {off }}$ and $\mathrm{SOA}_{\text {on }}$ were set by using Bias $=0 \mathrm{~V}$ and Bias $=1.8 \mathrm{~V}$, respectively. The SOAs presented less than $0.5 \mathrm{~dB}$ of polarization depending gain [34]. This resilience towards polarization variations allowed us to avert the use of polarization controllers before each amplifying stage. The switching time of the SOAs employed in this experiment has been reported to be less than 10ns [34]. The AWGs employed during the experiment matched the channel frequencies of the channels. The channel spacing of the AWGs was hence $100 \mathrm{GHz}$, matching the wavelength of the signals.

The four channels were fed into the optical switch, where they first experienced $10 \mathrm{~dB}$ gain through SOA1. The output of SOA1 was connected to AWG1. Since the experiment aims at emulating a single cluster with four channels, the filtered signals were recombined using 3 - $\mathrm{dB}$ couplers, to emulate a $400 \mathrm{GHz} \mathrm{AWG}$, not available in the lab. The signals were then fed into the second stage of the switch, consisting of SOA2 and AWG2, and then the third stage, consisting of SOA3 and AWG3. A variable optical attenuator (VOA) was introduced between the second and the third stage of the optical switch to avoid nonlinear effects due to saturation in SOA3. The dashed arrows at the output of the second and third stage represent changes in the physical interconnection; such changes were done in order to assess if signals were effectively switched.

Each switched signal was then fed into a receiver block, consisting of a $10 \mathrm{~dB}$ tap for monitoring, followed by a p-i-n photodiode, a digital sampling oscilloscope (DSO) operating at $40 \mathrm{GS} / \mathrm{s}$ and a digital signal processing (DSP) computational block to process off-line the stored data.

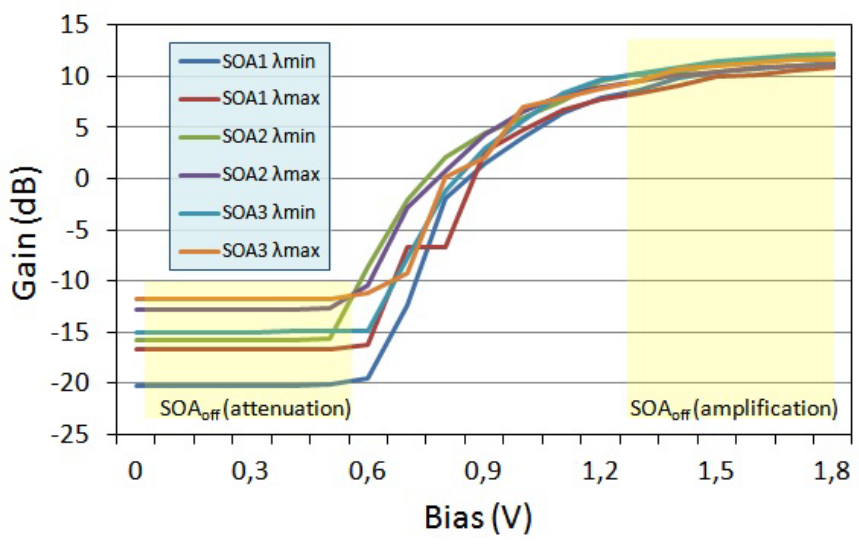

Fig. $\underline{5}$. Characterization of the SOAs employed in the experiment, for two different wavelengths $\left(\lambda_{\min }=1546,8 \mathrm{~nm}, \lambda_{\max }=1555,7 \mathrm{~nm}\right)$. The SOAs in the optical switch are operated either in the attenuation range $\left(\mathrm{SOA}_{\text {off }} \rightarrow \mathrm{Bias}=0 \mathrm{~V}\right)$ or the amplification range $\left(\mathrm{SOA}_{\mathrm{on}} \rightarrow\right.$ Bias $\left.=1,8 \mathrm{~V}\right)$.

\section{Results AND Discussion}

Considering the size of the optical switch and the number of channels, many output combinations can be set. During the experiments, we focused on the best and worst case scenario for each channel. The best case scenario corresponds to a unicast configuration in which a single channel is optically switched to the desired output port, while the rest of the channels are block by setting the last stage of SOAs (SOA3) off. The worst case corresponds to a multicast configuration in which the channel is broadcasted to all the output ports, by enabling all SOAs of the third stage. Figure $\underline{6}$ (a) represents visually the best and worst case scenarios for Channel 1, illustrating the presence of signals at each stage of the optical switch. Figure $\underline{6}(\mathrm{~b})$ shows the recovered constellations for Channel 1, for the back-to-back and the worst case scenario $(\mathrm{CH} 1 \mathrm{~B} 2 \mathrm{~B}$ and $\mathrm{CH} 1 \mathrm{ON}$, respectively). As it can be observed, the penalty on the constellation is perceivable but exiguous. 
a)

b)
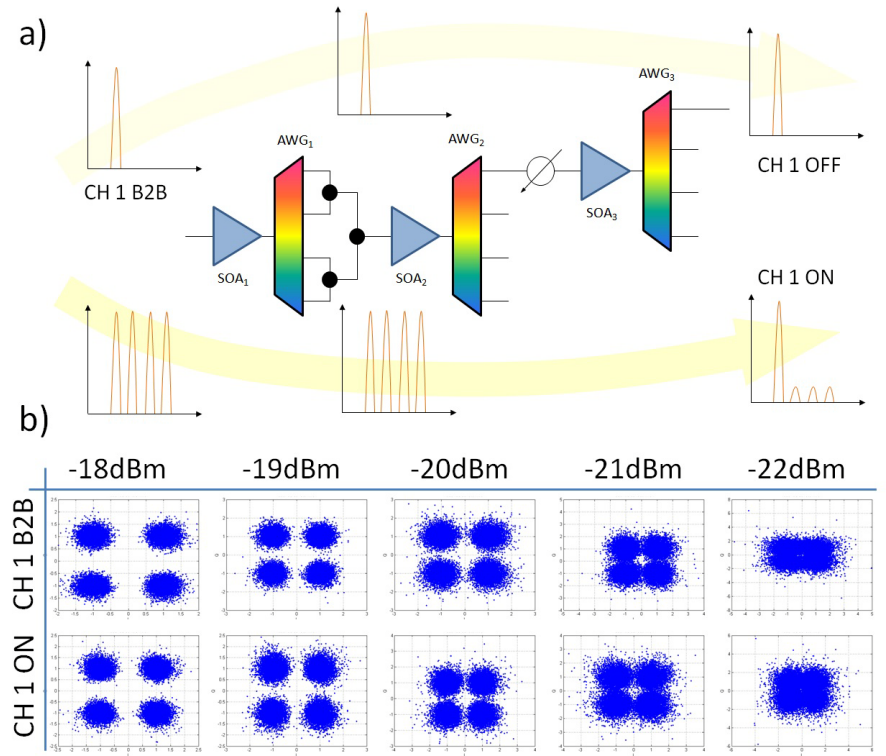

Fig. 6. A detail of the optical switch showing the presence of signals in the best case (CH1 OFF) and the worst case (CH $1 \mathrm{ON})$ (a), and plots of the constellations at the receiver side for $\mathrm{CH} 1$ at different optical powers (b). SOA: semiconductor optical amplifier, AWG: arrayed wave-guide.

Figure $\underline{7}$ shows the BER performance of all the channels. As it can be observed, the back-to-back (b2b) performance is only slightly degraded $(<0.5 \mathrm{~dB})$ when the channel is switched to the desired ouput in the best (OFF) and worst case (ON) scenarios, as the constellations in Fig. $\underline{6}(\mathrm{~b})$ augured. This result was expected since, as described in Section II.b., SOAs are not expected to induce any phase or amplitude degradation to the signals operating in the experimental range. Impairments are most likely to occur in case of bitrates one order of magnitude higher. The optical switch allows switching RoF signals based on current commercial standards without impairing their performance.

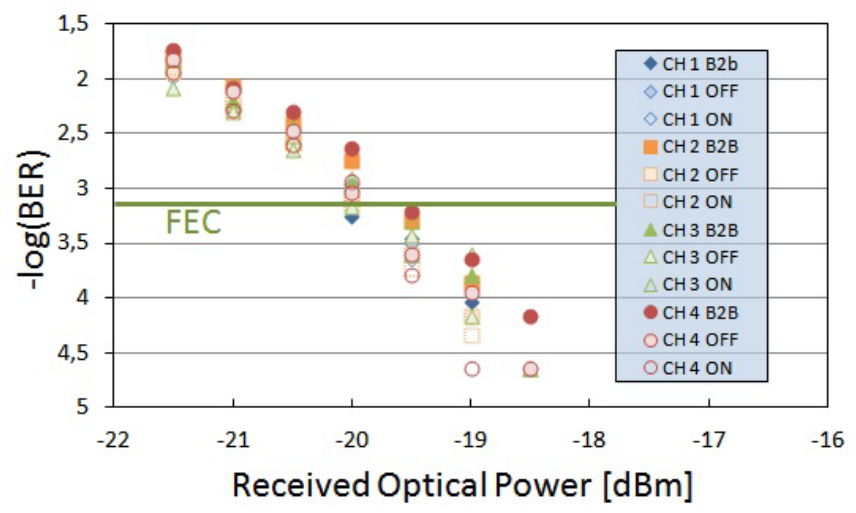

Fig. 7. BER performance of the system. The insets show the constellation of $\mathrm{CH} 1$ at the receiver side in the worst case scenario (rest of the channels ON). B2B: back-to-back, OFF: the other channels are set $\mathrm{OFF}$ by setting all $\mathrm{SOA}_{3} \mathrm{~S} \mathrm{OFF}$. ON: the other channels are set $\mathrm{ON}$ by setting all $\mathrm{SOA}_{3 \mathrm{~S}} \mathrm{ON}$. FEC: forward error correction.

An initial concern when designing the switch with SOAs was the possibility of distortion due to nonlinear effects and noise accumulation. The BER results indicate nonlinear effects have no impact on the signal, mainly due to the power levels handled by the switch; the signals are always maintained within the linear regime range of the SOAs. Noise accumulation, specifically ASE noise, plays a minor role thanks to the usage of AWGs, which filter any outband noise. Furthermore, since the RF signal has a frequency of only $5 \mathrm{GHz}$, fading effects due to dispersion during transmission are unlikely to occur.

\section{Conclusion}

An optical access network based on RoF technologies was presented and an experimental validation conducted. The experiment consisted in the implementation of a four channel system operating on a WiMax frequency band, and employing an OFDM-4QAM modulation at $625 \mathrm{Mbit} / \mathrm{s}$ per channel, transmission of the data over $20 \mathrm{~km}$ of optical fiber, and active switching in a one-by-sixteen active optical switch. The results reveal a negligible power penalty of less than $0.5 \mathrm{~dB}$ on each channel, for both the best and the worst case in terms of inter-channel crosstalk. The novelty of this work lays in the utilization of a highly reconfigurable and scalable, modulation format independent, optical switch initially designed for optical interconnections for distribution of wireless signals in access networks. This has a direct impact on how to avoid the bandwidth crunch predicted in [7].

Future work includes assessing the impact of nonlinearities induced by the SOA when higher order modulation formats are used (i.e. 16-, 32-, 64-QAM), or degradation due to noise accumulation because of SOA concatenation for higher number of stages. Furthermore, a smart upstream collection system needs to be designed since networks are bidirectional in their nature.

\section{ACKNOWLEDGMENT}

The EU commission is acknowledged for partly funding this research within the WISCON project of the Marie Curie program.

J.J. Vegas Olmos would like to acknowledge the contributions by L. Deng and X. Pang from DTU Fotonik, and F. Karinou and I. Roudas from the University of Patras.

\section{REFERENCES}

[1] D.L. Waring, J.W. Lechleider, T.R. Hsing, "Digital subscriber line technology facilitates a graceful transition from copper to fiber," IEEE Communications Magazine, Volume 29, Issue 3, pp. 96-104, 1991.

[2] M. Popov, C.P. Larsen, A. Gavler, P. Skoldstrom, and V. Nordell, "Advances in active optical networks (AON), results of the ICT ALPHA project" Stanford workshop, January, 2010.

[3] D.L. Waring, J.W. Lechleider, T.R. Hsing, "Digital subscriber line technology facilitates a graceful transition from copper to fiber," IEEE Communications Magazine, Volume 29, Issue 3, pp. 96-104, 1991.

[4] D. Simeonidou, R. Nejabati, G. Zervas, D. Klonidis, A. Tzanakaki, and M.J. O’Mahony, "Dynamic optical-network architectures and technologies for existing and emerging grid services," IEEE Journal of Lightwave Technology, Volume 23, Issue 10, pp. 3347-3357, October, 2005. 
[5] J. Kani, and N. Yoshimoto, "Next generation PONs: an operator's view", ECOC 2009, Vienna, Austria, 2009.

[6] L.G. Kazovsky, I. Tafur Monroy, S-W. Wong, and S-H. Yen, "Future evolution of broadband access: towards hybrid access networks," Access Nets 2008, Las Vegas, USA, 2008.

[7] Cisco Visual Network Index: Global Mobile Data Traffic Forecast Update, 2010-2015, http://newsroom.cisco.com/ekits/Cisco_VNI_Global_Mobile_Da ta_Traffic_Forecast_2010_2015.pdf

[8] J. E. Mitchell, "Radio over fibre networks: advances and challenges," ECOC 2009, paper 2.4.5, Vienna, Austria, 2009.

[9] A. Caballero, D. Zibar, R. Sambaraju, J. Marti, I. Tafur Monroy, "High-capacity $60 \mathrm{GHz}$ and $75-110 \mathrm{GHz}$ band links employing all-optical OFDM generation and digital coherent detection," IEEE Journal of Lightwave Technoloy, vol. 30, issue 1, pp. 147-155, 2012.

[10] C.W. Chow, C.H. Yeh, S. M. G. Lo, C. Li, and H. K. Tsang, "Long-reach radio-over-fiber signal distribution using singlesdeband signal generated by a silicon-modulator," Optics Express, Vol. 19, Issue 12, pp. 11312-11317, 2011.

[11] H-H. Yeh, C-W. Chow, Y-L. Liu, S-K. Wen, S-Y. Chen, C-R. Sheu, M-C. Tseng, J-L. Lin, D-Z. Hsu, and S. Chi, "Theory and technology for standard WiMAX over fiber in high speed train systems," IEEE Journal of Lightwave Technology, vol. 28, no. 16, pp.2327-2336, August, 2010.

[12] J.J. Vegas Olmos, T. Kuri, and K-I. Kitayama, "Half-duplex 12-channel dense WDM 2.6-GHz-band radio-over-fiber system employing a $1.5 \mathrm{GHz}$ bandwidth reflective semiconductor optical amplifier," OSA Journal of Optical Networking, vol. 7, no. 12, pp. 989-994, December, 2008.

[13] N. Madamopoulos, and A. Prescod, "Applications of large optical 3D MEMS switches in radio-over-fiber in-building networks," Photonics in Switching (PS) 2010, paper JTuB46, Monterey, USA, 2010.

[14] X. Qian, T. Lin, R.V. Penty, and I. H. White, "Novel SOAbased switch for multiple radio-over-fiber service applications," OFC 2006, paper JThB24, USA, 2006.

[15] A. Kaszubowska-Anandarajah, E. Connolly, L. P. Barry, and P. Perry, "Demonstration of wavelength packet switched radio-over-fiber system," IEEE Photonics Technology Letters, vol. 19, n. 4, pp. 200-202, February, 2007.

[16] D. Gutierrez, J. Cho, L.G. Kazovsky, "TDM-PON: security issue: upstream encryption is needed," OFC 2007, paper JWA83, Anaheim, USA, March, 2007.

[17] G.I. Papadimitriou, C. Papazoglou, and A. S. Pomportsis, "Optical switching: switch fabrics, techniques, and architectures," IEEE Journal of Lightwave Technology, vol. 21, no.2, pp. 384-405, February 2003.

[18] G.L. Yannitsos, and E.H. Hara, "SUPER-PBX: an optomechanical matrix switch," WESCANEX 88, Digital Communications Conference, pp. 108-110, 1988.

[19] S. Nagaoka, and Y. Suzuki, "Compact optomechanical switches and their applications in optical communication and testing systems," Micro Electro Mechanical Systems, MEMS'97, pp. 366-371, 1997.

[20] H. Zhu, P. Wang, and Z. Fan, "Evolutionary design optimization of MEMS: a brief review," IEEE International Conference on Industrial Technology (ICIT), pp. 1683-1687, 2010.

[21] Y. Kuratani, M. Kadota, "High-speed and low driving voltage LiNbO3 optical switch composed of new structure," OSA Conference on Lasers and Electro-Optics (CLEO) and Quantum Electronics and Laser Science Conference (QELS), paper JThE73, 2010.

[22] N. Chi, J.J. Vegas Olmos, K. Thakulsukanant, Z. Wang, O. Ansell, S. Yu, and D. Huang, "Experimental characteristics of optical crosspoint switch matrix and its applications in optical packet switching," IEEE Journal of Lightwave Technology, vol. 24, No. 10, pp. 3646-3653, October 2006.

[23] A. Biberman, H.L.R. Lira, K. Padmaraju, N. Ophir, J. Chan, M. Lipson, K. Bergman, "Broadband silicon photonic electrooptic switch for photonic interconnection networks,"
IEEE Photonics Technology Letters, vol. 23, No. 8, April 15, 2011.

[24] Q. Fang, J.F. Song, T-Y. Liow, H. Cai, M.B. Yu, G. Q. Lo, and D-L. Kwong, "Ultralow power silicon photonics thermo-optic switch with suspended phase arms," IEEE Photonics Technology Letters, vol. 23, No. 8, pp. 525-527, April 2011.

[25] S. J. Ben Yoo, "Optical Packet and Burst Switching Technologies for the Future Photonic Internet," IEEE Journal of Lightwave Technology, vol. 24, n. 12, pp. 4468-4492, December 2006.

[26] X. Ma, and G.-S. Kuo, "Optical switching technology comparison: optical MEMS vs. other technologies", IEEE Communications Magazine, vol. 41, issue 11, pp. S16-S23, 2003.

[27] K. Morito, "Optical switching devices based on semiconductor optical amplifiers," International Conference on Photonics in Switching, PS'09, pp. 1-2, Sept. 2009.

[28] R. Hemenway et al., "Optical packet-switched interconnect for supercomputer applications," OSA Journal of Optical networking, vol. 3, pp. 900-913, December, 2004.

[29] I. Roudas, B.R. Hemenway, and R.R. Grzybowski, "Optimization of a supercomputer optical interconnect architecture," IEEE LEOS Annual Meeting, paper ThG3, Orlando, FL, October, 2007.

[30] J. J. Vegas Olmos, T. Kuri, T. Sono, K. Tamura, H. Toda, and K. Kitayama, "Wireless and optica-integrated access network with peer-to-peer connection capability," IEEE Photon. Technol. Lett., vol.20, no.13, pp.1127-1129, July 2008.

[31] K. Wakayama, C. Hasegawa, D. Ishii, and N. Yamanaka, "Evaluation of prototype for 10gbps Active Optical Access System,"OptoElectronics and Communications Conference (OECC), paper 8A4-3, pp. 436-437, 2010.

[32] A. Rohit, A. Albores-Mejia, J. Bolk, X.J.M. Leijtens, and K.A. Williams, "Multi-path routing in a monolithically integrated $4 \mathrm{x} 4$ broadcast and select WDM cross-connect," ECOC 2011, paper Mo.2.1., 2011.

[33] R. J. Manning, R. Giller, X. Yang, R. P. Webb, and D. Cotter, "SOAs for all-optical switching-techniques for increasing the speed," ICTON 2007, paper Th.A2.1, 2007.

[34] R. Luijten, W.E. Denzel, R.R. Grzybowski, R. Hemenway, "Optical interconnection networks: The OSMOSIS project," Lasers and Electro-Optics Society, 2004. LEOS 2004. The 17th Annual Meeting of the IEEE, vol. 2, pp. 563-564, 2004. 